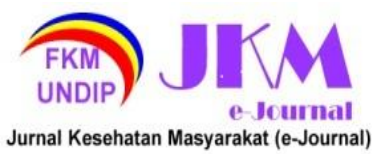

JURNAL KESEHATAN MASYARAKAT (e-Journal)

Volume 10, Nomor 1, Januari 2022

ISSN: 2715-5617 / e-ISSN: 2356-3346

http://ejournal3.undip.ac.id/index.php/jkm

\title{
IDENTIFIKASI RISIKO ERGONOMI PADA PEKERJA UD. SATRIA
}

\author{
Mohamad Nurhamzah Ramadani ${ }^{1 *}$, Merry Sunaryo ${ }^{1}$ \\ ${ }^{1}$ Program Studi Keselamatan dan Kesehatan Kerja, Fakultas Kesehatan Universitas Nahdlatul Ulama Surabaya \\ *Corresponding author: mohamadnurhamzah019.k318@student.unusa.ac.id
}

\begin{abstract}
UD. Satria is an industry engaged in the manufacture of sandals that has been in production since the 1980s, which is located in the Waru area, Sidoarjo. UD. Satria accepts the production of sandals according to demand such as children's sandals or adult sandals as well as being a distributor for big shops in Sidoarjo and also online shops. In running this sandal business industry, UD. Satria has 7 workers who work 8 hours per day and still use manual processes in their production. Which means it has the potential for musculoskeletal complaints. Observation and data collection carried out is primary data collection. Which is where the data obtained directly from the respondents. After the field survey, it was found that it was necessary to collect data on Musculoskeletal Disorders (MSDs) using a questionnaire using the Nordic Body Map (NBM) method and followed by measuring work posture using the RULA (Rapid Upper Limb Assessment) method. Many workers complain of back and neck pain, it can be caused by the wrong work posture. Therefore, an ergonomic risk assessment was carried out, with the aim of identifying the level of complaints of musculoskeletal disorders (MSDs). As well as making efforts to reduce the risk of MSDs complaints that can affect the productivity level of UD. Satria workers.
\end{abstract}

Keywords: Musculoskeletal Disorders, Nordic Body Map, Ergonomics, RULA (Rapid Upper Limb Assessment)

\section{PENDAHULUAN}

Pada zaman modern saat ini, perekmbangan pada dunia industri dan perdagangan belakangan ini sangat cepat. Penggunaan teknologi juga semakin meningkat, Hal ini juga didukung semakin banyaknya industri yang menggunakan teknologi dalam setiap proses produksinya. Meskipun industri di Indonesia banyak menggunakan teknologi modern, Tidak dapat dipungkiri bahwa masih terdapat beberapa proses yang memerlukan tenaga manusia dalam penanganannya atau manual handling. ${ }^{(1)}$

Sebagai negara berkembang, Indonesia memerlukan sumber daya manusia yang sehat, effisien serta produktif dalam melakukan pembangunan nasional. Selain itu, tenaga kerja adalah unsur yang langsung berhadapan dengan macam-macam akibat dari perkembangan tekhnologi dibidang industri, sehingga wajib kepada mereka diberikan perlindungan pemeliharaan kesehatan dan pengembangan terhadap kesejahteraan atau jaminan nasional ${ }^{(2)}$

Banyak industri yang masih menggunakan tenaga manusia pada proses produksi nya, misalkan pada proses pemotongan bahan, pengeleman, pengepakan dan pengangkutan hasil produksi. Pekerjaan tersebut sangat dipengaruhi oleh beban dari benda yang diangkut, cara mengangkat, posisi mengangkat, jarak tempuh mengangkat, hingga frekuensi mengangkat. Apabila salah satu proses dilakukan dengan prosedur yang kurang benar, akan mengakibatkan rasa sakit, terutama pada punggung maupun anggota badan yang lainnya. Pada ilmu ergonomi, gangguan atau keluhan yang berhubungan dengan sistem otot dan tulang belakang disebut dengan musculoskeletal disorders (MSDs).

Proses kerja yang dilakukan secara berulang-ulang, membutuhkan waktu yang lama, dan dengan postur kerja tidak ergonomis akan mengakibatkan timbulnya gangguan pada tubuh seperti kelelahan kronis dan Musculoskeletal Disorders $^{(3)}$

Keluhan musculoskeletal disorders (MSDs) jika tidak cepat dilakukan penanganan dapat mengganggu konsentrasi saat bekerja, menyebabkan kelelahan sehingga akan menurunkan produktivitas pekerja itu sendiri ${ }^{(4)}$

Dengan adanya keluhan-keluhan rasa sakit ini menjadi seharusnya menjadi perhatian yang serius terhadap isu-isu ergonomi dan keterkaitannya dengan ancaman MSDs (Musculoskeletal disorders). ${ }^{(5)}$

Dampak yang dapat diakibatkan oleh musculoskeletal disorders (MSDs) pada aspek produksi ialah akan berkurangnya output, kerusakan material produk yang dapat mengakibatkan tidak terpenuhinya target produksi dan juga pelayanan tidak memuaskan. Selain itu, biaya yang diakibatkan oleh absensi atau pekerja yang tidak masuk kerja akan menimbulkan penurunan keuntungan. Hal ini disebabkan oleh pengeluaran biaya untuk mengadakan pelatihan karyawan baru untuk menggantikan karyawan lama yang sedang sakit serta biaya untuk menyewa jasa konsultan dan agen lainnya. ${ }^{(6)}$

UD. Satria merupakan industri yang bergerak dibidang manufaktur produksi sandal yang sudah berproduksi sejak tahun 1980-an, yang berada di daerah Waru, Sidoarjo. UD. Satria ini menerima produksi sandal sesuai dengan permintaan seperti 


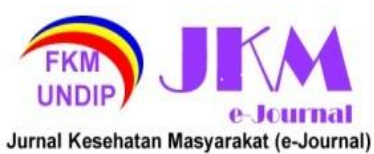

sandal anak-anak ataupun sandal dewasa sekaligus menjadi distributor bagi toko-toko besar di sidoarjo dan juga online shop. Dalam menjalankan industri usaha sandal ini, UD. Satria memiliki 7 pekerja dan masih menggunakan proses manual dalam produksinya. Pada wawancara yang telah dilakukan kepada pekerja mengalami banyak keluhan nyeri otot, dan sakit pada bagian punggung dan leher

Musculoskeletal Disorders (MSDs) adalah sekumpulan gejala atau gangguan yang berkaitan dengan jaringan otot, tendon, ligament, kartilago, sistem saraf, struktur tulang, dan pembuluh darah. MSDs pada awalnya menyebabkan sakit, nyeri, mati rasa, kesemutan, bengkak, kekakuan, gemetar, gangguan tidur dan rasa terbakar. ${ }^{(7)}$

Keluhan sistem musculoskeletal pada umumnya terjadi karena kontraksi otot yang berlebihan akibat pemberian beban kerja yang terlalu berat dengan durasi pembebanan yang panjang. ${ }^{(4)}$

Dari permasalahan tersebut, maka selanjutnya dilakukan penilaian risiko ergonominya, dengan tujuan untuk mengidentifikasi tingkat keluhan musculoskeletal disorders (MSDs). Serta melakukan upaya untuk mengurangi risiko keluhan MSDs yang dapat mempengaruhi tingkat produktivitas pekerja UD. Satria.

\section{METODE PENELITIAN}

Pada penelitian ini menggunakan metode kuantitatif deskriptif. Penelitian kuantitatif deskriptif (Descriptive Quantitative Research) digunakan untuk menggambarkan, menjelaskan, atau meringkaskan berbagai kondisi, situasi, fenomena, atau berbagai variabel penelitian menurut kejadian sebagaimana adanya yang dapat dipotret, diwawancara, diobservasi, serta yang dapat diungkapkan melalui bahan-bahan dokumenter. Tujuan penelitian kuantitatif deskriptif adalah untuk menjelaskan suatu situasi yang hendak diteliti dengan dukungan studi kepustakaan sehingga lebih memperkuat analisa peneliti dalam membuat suatu kesimpulan, tanpa membuat perbandingan atau menghubungan dengan variabel lainnya. Penelitian ini dilakukan pada proses pekerjaan di salah satu sektor industri informal yang bergerak dibidang manufaktur produksi sandal yaitu UD. Satria yang berada di Kabupaten Sidoarjo. pengambilan data mengenai Muskuloskeletal Disorders (MSDs) menggunakan kuesioner metode Nordic Body Map (NBM) yang merupakan metode penilaian untuk mengukur dan mengetahui sakit pada bagian tubuh pekerja.

Nordic Body Map (NBM) berupa kuesioner yang paling sering digunakan untuk mengetahui ketidaknyamanan atau kesakitan pada tubuh, Responden yang mengisi kuesioner diminta untuk memberikan tanda ada tidaknya gangguan pada bagian area tubuh tersebut ${ }^{(8)}$

Kuesioner Nordic Body Map merupakan salah satu bentuk kuesioner checklist ergonomi yang sudah banyak digunakan untuk mengetahui ketidaknyamanan pada para pekerja, dan alasan kuesioner ini banyak digunakan kare sudah terstandarisasi dan juga tersusun rapi. Sampel pada penelitian ini berjumlah 7 responden yang terdiri dari beberapa unit kerja. Kemudian, dilakukan analisis data dengan melakukan perhitungan nilai risiko sesuai dengan metode NBM ini.Kuesioner NBM dapat dilihat pada tabel 1 .

Tabel 1. Kuesioner Nordic Body Map 


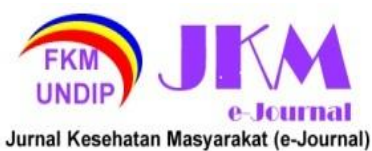

\author{
JURNAL KESEHATAN MASYARAKAT (e-Journal) \\ Volume 10, Nomor 1, Januari 2022 \\ ISSN: 2715-5617 / e-ISSN: 2356-3346 \\ http://ejournal3.undip.ac.id/index.php/jkm
}

PETUNJUK PENGISIAN KUESIONER

Jawablah pertanyaan di bawah ini berdasarkan keluhan yang anda rasakan dengan memberi tanda ( $\checkmark$ ) pada kolom Jwaban dengan kriteria sebagai berikut:

TS $=$ Tidak Sakit

$\begin{aligned} \text { AS } & =\text { Agak Sak } \\ & =\text { Sakit }\end{aligned}$

SS $=$ Sakit sekali

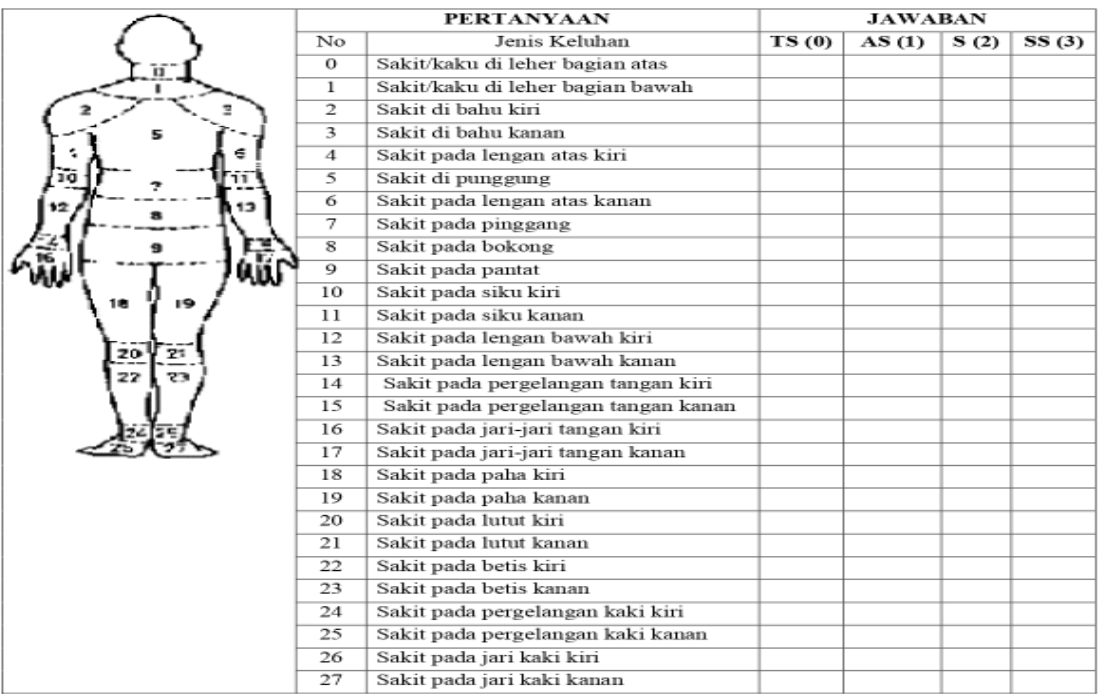

Penilaian dilakukan pada tiap responden di semua unit kerja dengan skala likert yang telah ditentukan. Klasifikasi skala likert tersebut terdiri dari 4 nilai dan terletak pada lembar kuesioner(9). Skala penilaian tersebut dapat dilihat pada tabel 2 .

Tabel 2. Klasifikasi Skala Likert Nordic Body Map

\begin{tabular}{cl}
\hline Skala Likert & \multicolumn{1}{c}{ Keterangan } \\
\hline 0 & $\begin{array}{l}\text { Tidak ada keluhan atau kenyerian atau tidak ada rasa sakit } \\
\text { sama sekali yang dirasakan (Tidak Sakit) }\end{array}$ \\
\hline 1 & $\begin{array}{l}\text { Dirasakan sedikit adanya keluhan atau kenyerian pada otot } \\
\text { skeletal (Agak Sakit) }\end{array}$ \\
\hline 2 & $\begin{array}{l}\text { Responden merasakan adanya keluhan atau kenyerian atau } \\
\text { sakit pada otot skeletal (Sakit) }\end{array}$ \\
\hline 3 & $\begin{array}{l}\text { Responden merasakan keluhan sangat sakit atau sangat } \\
\text { nyeri pada otot skeletal (Sangat Sakit) }\end{array}$ \\
\hline
\end{tabular}

Sumber: Tarwaka, 2015

Selanjutnya, dilakukan penjumlahan terhadap keseluruhan skor dan nilainya akan disesuaikan dengan tabel klasifikasi tingkat risiko MSDs.
Berikut adalah tabel klasifikasi tingkat risiko MSDs yang ditunjukkan pada Tabel 3.(9)

Tabel 3. Klasifikasi Tingkat Risiko Berdasarkan Total Skor Individu

\begin{tabular}{cc}
\hline Total Skor Individu & Tingkat Risiko MSDs \\
\hline $0-20$ & Rendah \\
\hline $21-41$ & Sedang \\
\hline $42-62$ & Tinggi \\
\hline $62-84$ & Sangat Tinggi \\
\hline
\end{tabular}

Sumber: Tarwaka, 2015

Dilanjutkan dengan pengukuran postur kerja menggunakan metode RULA (Rapid Upper Limb Assessment) untuk mengetahui postur kerja sebagai penyebab risiko ergonomi. Metode RULA dirancang untuk kemudahan tanpa memerlukan alat 


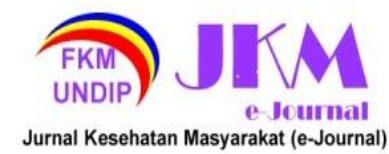

\author{
JURNAL KESEHATAN MASYARAKAT (e-Journal) \\ Volume 10, Nomor 1, Januari 2022 \\ ISSN: 2715-5617 / e-ISSN: 2356-3346 \\ http://ejournal3.undip.ac.id/index.php/jkm
}

yang sulit digunakan. Menggunakan table action level RULA, yang ditunjukkan pada gambar berikut:

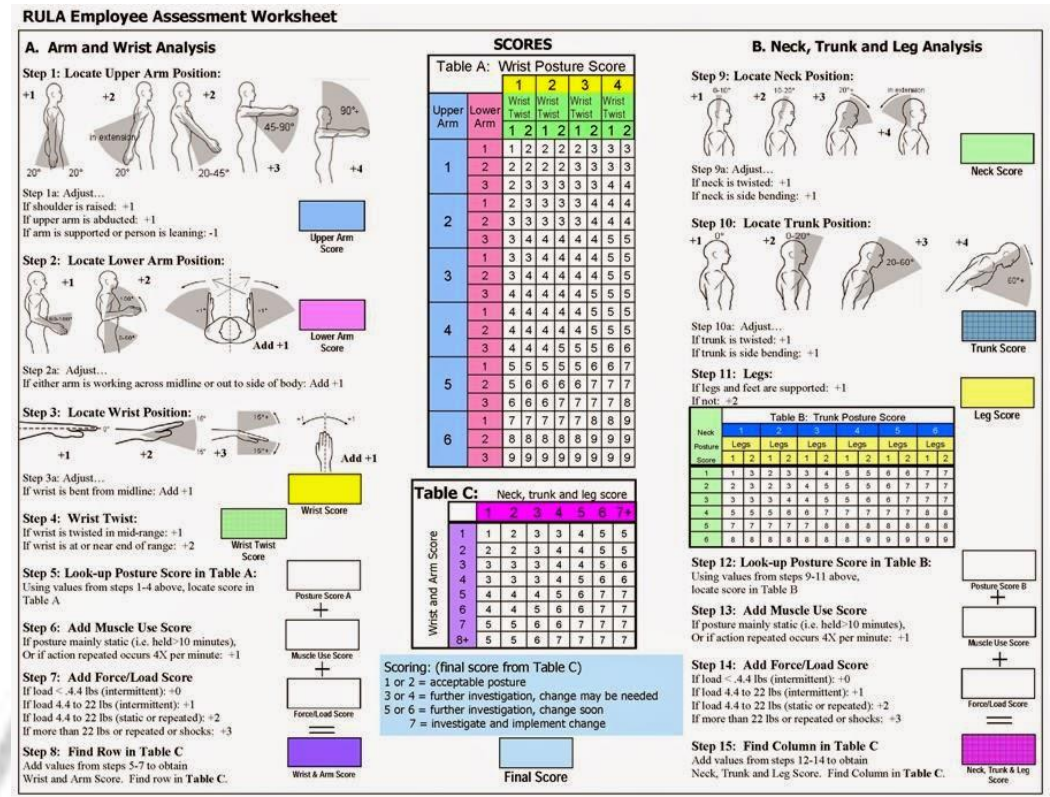

Sumber: Dr. Alan Hedge 1963

Setelah itu, dari hasil skor di beberapa bagian tubuh itu ditambahkan dan didapatkan hasil skor akhir yang nantinya akan disimpulkan menjadi jenis

pekerjaan yang di lakukan termasuk dalam beberapa kategori dalam tabel berikut, yaitu:

Tabel 4. Nilai RULA

\begin{tabular}{|c|l|}
\hline Skor & \multicolumn{1}{|c|}{ Tingkat Risiko } \\
\hline $1-2$ & Resiko diabaikan, tidak perlu penanganan \\
\hline $3-4$ & Resiko rendah, perubahan dibutuhkan \\
\hline $5-6$ & Resiko sedang, pananganan lebih lanjut, butuh perubahan \\
\hline $6+$ & Sangat beresiko, lakukan perubahan sekarang \\
\hline
\end{tabular}

\section{HASIL DAN PEMBAHASAN}

Penelitian dilakukan di UD. Satria yang bergerak dalam industri pembuatan sandal karet. UD. Satria mengolah lembaran spons menjadi produk berupa sandal, lembaran spons diperoleh dari supplier. Hasil produksi sendiri dikirim ke toko-toko besar di Sidoarjo dan Surabaya dan juga online shop. UD. Satria memproduksi sandal yang terdiri dari bermacam-macam warna dan ukuran yaitu untuk anak-anak dan juga dewasa. Proses produksi di UD. Satria terdapat 7 tahap, yaitu penempelan gambar pada lembaran spons, pencetakan dan pemotongan, pengeleman, pelubangan sandal, perakitan sandal, penghalusan bagian samping sandal dengan gerinda, dan proses packing. UD. Satria sendiri memiliki pekerja sebanyak 7 orang dengan berbagai jenis pekerjaan masing- masing yang dilakukan.

Proses awal yang dilakukan adalah melakukan pengamatan ketika sedang melakukan proses produksi. Kemudian melakukan tanya dan jawab mengenai kuisioner NBM kepada 7 pekerja. Setelah dilakukan pengambilan data berupa kuisioner dengan 7 sampel pekerja UD. Satria, berikut adalah hasil dari pengumpulan data yang telah dilakukan:

\section{UMUR}

Umur para pekerja di UD. Satria berkisar antara 30-60 tahun. Gambaran umur responden dapat ditunjukkan pada tabel berikut:

Tabel 5. Karakteristik Umur Responden

\begin{tabular}{ccc}
\hline Umur & Frekuensi & Presentase \\
\hline $30-40$ tahun & 3 & $43 \%$ \\
\hline $41-51$ tahun & 3 & $43 \%$ \\
\hline$>52$ tahun & 1 & $14 \%$ \\
\hline Total & 7 Orang & $100 \%$ \\
\hline
\end{tabular}

Sumber: Data Primer, 2021

Dari tabel 5, dapat dilihat bahwa jumlah responden terbanyak pada kategori umur 30-45 


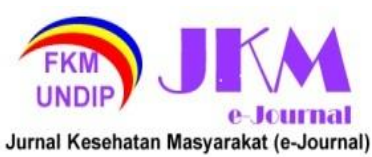

tahun dan 46-51 tahun dengan jumlah responden masing-masing 3 orang (43\%) dan jumlah yang paling sedikit terdapat pada kategori lebih dari 52 tahun dengan jumlah responden sebanyak 1 orang $(14 \%)$.

\section{PENDIDIKAN TERAKHIR}

Pendidikan terakhir pekerja terdiri dari SD hingga SMA. Gambaran umur responden dapat ditunjukkan pada tabel berikut:

Tabel 6. Karakterisitik Pendidikan Terakhir Responden

\begin{tabular}{ccc}
\hline $\begin{array}{c}\text { Pendidikan } \\
\text { Terakhir }\end{array}$ & Frekuensi & Presenatse \\
\hline SD & 3 & $43 \%$ \\
\hline SMP & 0 & $0 \%$ \\
\hline SMA & 4 & $57 \%$ \\
\hline Total & 7 Orang & $100 \%$ \\
\hline \multicolumn{2}{c}{ Sumber: Data Primer, 2021}
\end{tabular}

Dari tabel 6, dapat dilihat bahwa jumlah responden yang berpendidikan SMA sebanyak 4 $(57 \%)$ dan responden yang pendidikan terakhirnya SD sebanyak 3 orang (43\%).

\section{LAMA KERJA DALAM SEHARI}

Gambaran lama kerja dalam sehari dari responden dapat ditunjukkan pada tabel berikut:

Tabel 7. Karakteristik Lama Kerja Responden

\begin{tabular}{ccc}
\hline Lama Kerja & Frekuensi & Presenatse \\
\hline$<8$ Jam & 0 & $0 \%$ \\
\hline 8 Jam & 7 & $100 \%$ \\
\hline Total & 7 Orang & $100 \%$ \\
\hline
\end{tabular}

Sumber: Data Primer, 2021

Dari tabel 7, dapat dilihat bahwa jumlah responden yang bekerja selama 8 jam dalam sehari sebanyak 7 orang $(100 \%)$.

\section{TINGGI BADAN}

Tinggi badan pekerja terdiri dari $155 \mathrm{~cm}$ hingga $165 \mathrm{~cm}$. Gambaran tinggi badan responden dapat ditunjukkan pada tabel berikut:

Tabel 8. Karakteristik Tinggi Badan Responden

\begin{tabular}{ccc}
\hline $\begin{array}{c}\text { Tinggi } \\
\text { Badan }\end{array}$ & Frekuensi & Presenatse \\
\hline $155-160$ & 5 & $71 \%$ \\
\hline $161-165$ & 2 & $29 \%$ \\
\hline Total & 7 Orang & $100 \%$ \\
\hline
\end{tabular}

Sumber: Data Primer, 2021

Dari tabel 8, dapat dilihat bahwa jumlah responden dengan tinggi badan $155-160 \mathrm{~cm}$ sebanyak $5(71 \%)$ dan jumlah responden dengan tinggi badan 161-165 cm sebanyak 2 orang (29\%).

\section{BERAT BADAN}

Berat badan pekerja terdiri dari $45 \mathrm{~kg}$ hingga $70 \mathrm{~kg}$. Gambaran berat badan responden dapat ditunjukkan pada tabel berikut:

Tabel 9. Karakteristik Berat Badan Responden

\begin{tabular}{ccc}
\hline $\begin{array}{c}\text { Berat } \\
\text { Badan }\end{array}$ & Frekuensi & Presenatse \\
\hline $45-50$ & 3 & $43 \%$ \\
\hline $51-55$ & 2 & $29 \%$ \\
\hline $56-60$ & 1 & $14 \%$ \\
\hline$>61$ & 1 & $14 \%$ \\
\hline Jumlah & 7 Orang & $100 \%$ \\
\hline \multicolumn{3}{c}{ Sumber: Data Primer, 2021}
\end{tabular}

Dari tabel 9, dapat dilihat bahwa jumlah responden dengan berat badan 45-50 kg sebanyak 3 (43\%), lalu jumlah responden dengan berat badan $51-55 \mathrm{~kg}$ sebanyak 2 orang (29\%) dan jumlah responden dengan berat badan 56-60 dan lebih dari 61 masing-masing sebanyak 1 orang (14\%).

HASIL IDENTIFIKASI MUSCULOSKELETAL DISORDER (MSDS) DENGAN METODE NORDIC BODY MAP (NBM)

Berdasarkan hasil data dalam persentase keluhan sakit yang dialami oleh pekerja UD. Satria menunjukkan hasil skor pada kategori tidak sakit persentase terbesar dengan nilai $86 \%$ pada lengan atas kiri, kategori agak sakit terbesar dengan nilai $57 \%$ pada bagian lengan atas kanan, lengan bawah kanan dan lutut kiri, kategori sakit terbesar dengan nilai $100 \%$ pada leehr bagian atas dan leher bagian bawah, kategori sangat sakit terbesar dengan nilai $57 \%$ pada bagian pinggang.

Pada perhitungan skor individu dengan skala likert yang sudah ditentukan mendapatkan hasil skor mulai dari yang terendah yaitu skor 27 dan yang tertinggi yaitu skor 38 .

Lalu dari data kuesioner Nordic Body Map yang telah dilakukan para responden mendapatkan total skor individu dengan tabel sebagai berikut:

Tabel 10 Hasil Total Skor Individu Responden Nordic Body Map

\begin{tabular}{lc}
\hline \multicolumn{1}{c}{ Responden } & Hasil \\
\hline Responden 1 & 38 \\
Responden 2 & 35 \\
Responden 3 & 30 \\
Responden 4 & 27 \\
Responden 5 & 31 \\
Responden 6 & 29 \\
Responden 7 & 37 \\
\hline
\end{tabular}

Dari tabel 9, dapat dilihat bahwa dari perhitungan skor individu dengan skala likert yang sudah ditentukan mendpatkan hasil skor mulai dari yang terendah yaitu skor 27 dan yang tertinggi yaitu skor 38 . 


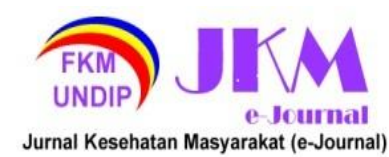

Selanjutnya skor tersebut ditentukan melalui klasifikasi subjektivitas tingkat risiko otot skeletal berdasarkan hasil total skor individu yang didapatkan. Dan memiliki hasil pada table berikut:

Tabel 11. Klasifikasi Responden Sesuai Dengan Hasil Total Skor

\begin{tabular}{lc}
\hline Responden & Klasifikasi \\
\hline Responden 1 & Sedang \\
Responden 2 & Sedang \\
Responden 3 3 & Sedang \\
Responden 4 & Sedang \\
Responden 5 & Sedang \\
Responden 6 & Sedang \\
Responden 7 & Sedang \\
\hline
\end{tabular}

Dari tabel 10, dapat dilihat bahwa klasifikasi subjektivitas tingkat risiko otot skeletal pada para responden mendapatkan hasil sedang seluruhnya. ${ }^{(9)}$

Hal ini dikarenakan pekerjaan yang dilakukan oleh pekerja secara manual sehingga hal ini memberikan beban otot yang berat kepada pekerja terhadap peningkatan keluhan sistem muskuloskeletal. $^{(10)}$

Ramdhani (2017), dalam penelitiannya menyebutkan pada pengrajin hadycraft yang bekerja dengan posisi postur tubuh duduk dilantai mengalami keluhan sangat sakit dengan presentase paling besar yaitu $100 \%$ pada bagian punggung dan pinggang, $67 \%$ pda bagian leher atas. Dari keluhankeluhan yang dirasakan oleh pekerja dapat menyebabkan penurunan produktivitas dari pekerja. Presentase keluhan yang dirasakan oleh pekerja akan semakin meningkat apabila pekerjaan tersebut dilakukan dengan terus menerus dan dalam waktu yang lama. ${ }^{(11)}$
Hal ini sejalan dengan penelitian Sujoso dan Rika (2009), bahwa bekerja dengan duduk dengan sikap selalu membungkuk sering mendapat keluhan musculoskeletal pada beberapa bagian tubuh yaitu leher, punggung bawah dan pinggang. ${ }^{(12)}$

Beberapa jenis penyakit yang dapat mempengaruhi terjadinya Musculoskeletal Disorders antara lain adalah osteoporosis karena berkurangnya kepadatan massa tulang, penyakit jantung karena ketidakseimbangan kebutuhan oksigen pada tubuh, penyakit ginjal karena gangguan metabolisme, tekanan darah rendah karena terbentuknya asam laktat, dan tekanan darah tinggi karena terhambatnya aliran darah ${ }^{(3)}$

Jika keluhan tersebut dibiarkan saja secara terus menerus, selain pekerja yang rugi, perusahaan pun akan menurun tingkat produktivitasnya. Pencegahan yang dapat dilakukan untuk mengurangi keluhan musculoskeletal disorders yaitu dengan cara meregangkan otot setiap jam istirahat atau beberapa jam sekali dan melakukan pemanasan sesaat sebelum memulai pekerjaan, jika mengalami sakit yang berlebihan pada bagian tubuh sebaiknya pergi ke rumah sakit atau klinik unuk mendapatkan penanganan yang lebih lanjut.

IDENTIFIKASI POSTUR KERJA DENGAN METODE RULA (RAPID UPPER LIMB ASSESMENT)

Pengukuran yang dilakukan menggunakan metode RULA, karena metode ini menilai posisi kerja yang dilakukan oleh tubuh bagian atas. Dengan hasil berikut ini:

Tabel 12. Grand Score RULA pada pekerja UD. Satria

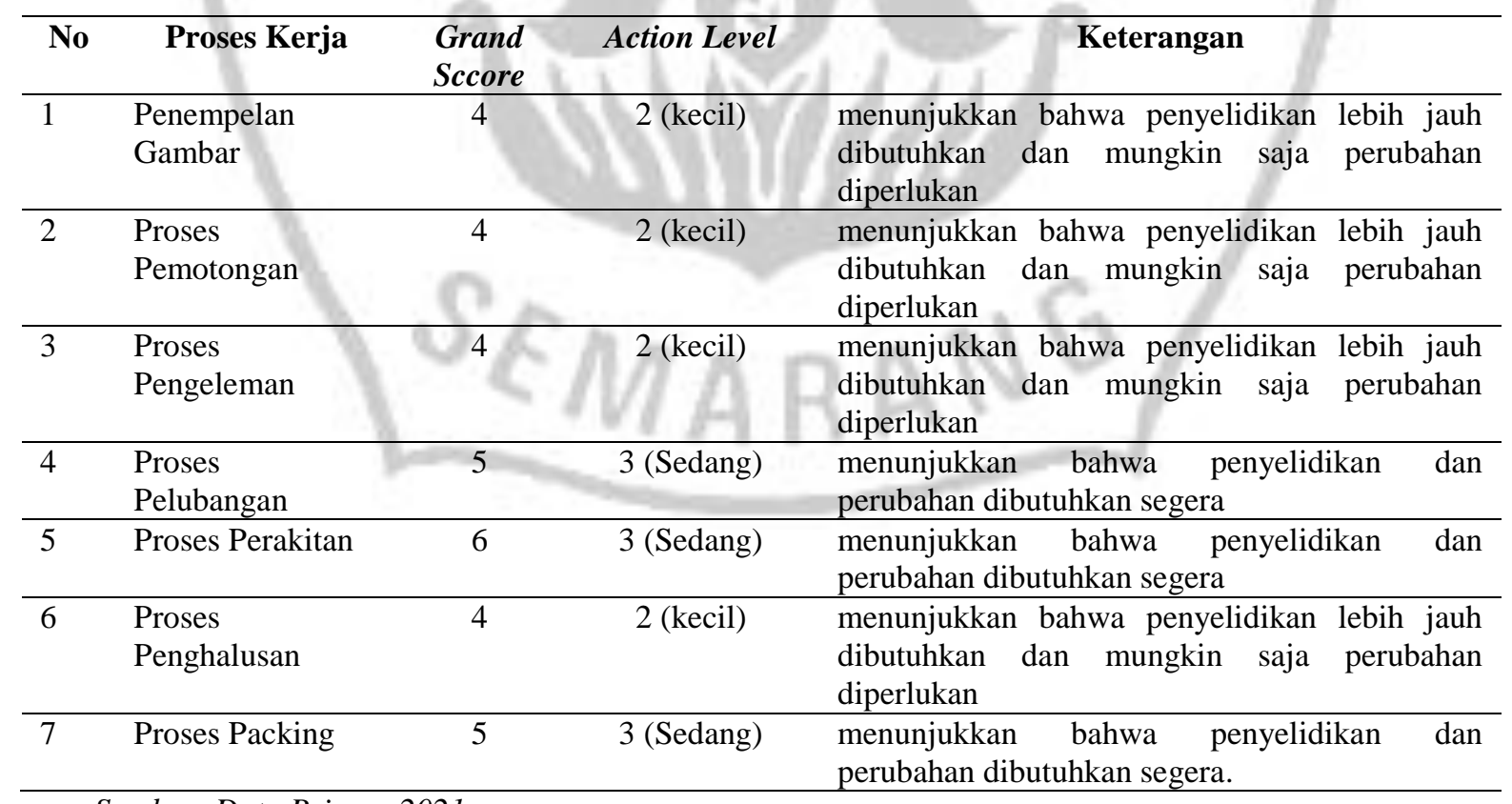

Sumber: Data Primer, 2021 


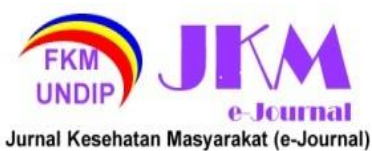

Pada unit kerja penempelan gambar, pemotongan, pengeleman, penghalusan, dan packing mendapatkan grand score 4 yang menunjukkan action level 2. Artinya bahwa dibutuhkan penyelidikan lebih jauh dan mungkin saja perubahan diperlukan. Sedangkan pada proses pelubangan dan perakitan mendapatkan grand score 5 untuk proses pelubangan dan grand score 6 untuk proses perakitan. Keduanya mendapat action level 3 , yang artinya adalah penyelidikan dan perubahan dibutuhkan segera. Dari identifikasi tersebut dapat diketahui bahwa banyak postur-postur yang memungkinkan pekerja tidak nyama dengan adanya postur kerja yang tidak alamiah. Maka dari itu perlu adanya perubahan dari postur kerja dan alat bantunya ${ }^{(9)}$

Sikap kerja tidak alamiah akan mempercepat otot mengalami mudah kelelahan sehingga akan cenderung terjadinya muskuloskeletal disorders. Maka harus cepat untuk dilakukan perubahan dengan cara sebagai berikut: Pertama, stasiun kerja harus mudah disesuaikan terhadap pengguna dan didesain harus sesuai dengan pekerjaan. Hal ini sudah dapat dipenuhi dengan desain Bed tempat tidur pasien yang bisa di naik turunkan sesuai posisi kerja yang ergonomi. Kedua, pada saat melakukan pekerjaan dalam hal ini melakukan saat melakukan tindakan ke pasien dalam posisi membungkuk (sudut $20^{\circ}-60^{\circ}$ ) sehingga berdasar hasil skor dengan metode RULA berada di level 2. Maka untuk mengurangi hal itu sebaiknya dengan posisi membungkuk bisa menggunakan alat bantu kursi ${ }^{(13)}$

Hasil penelitian ini pun sejalan dengan penelitian sebelumnya mengenai keluhan MSDsatau nyeri otot pada pekerja pembuatan paving dan batako, yang menyebutkan bahwa postur kerja yang salah merupakan faktor yangmenyebabkan keluhan MSDs atau nyeri otot. Hasil keluhan yan dirasakan adalah pegal pada leher, nyeri pada punggung, pegal pada bahu, pegal pada tangan, nyeri pada lutut, kesemutan pada kaki, dimana keluhan tersebut terjadi akibat posisi leher menekuk, jongkok, badan membungkuk, mengangkat dan kegiatan memukul yang dilakukan secara berulang dan cara kerja tersebut serupa dengan cara kerja pada pabrik tahu $\mathrm{X}$ di Kota Semarang. ${ }^{(14)(15)}$

Atau pemilik usaha merubah metode kerja yang sudah ada dengan metode yang lebih baik, karena menurut Briansah (2018) Metode kerja yang kurang baik juga sangat mempengaruhi tingkat kelelahan dan produktifitas para pekerja. Para pekerja terkadang kinerja mereka tidak maksimal dan sering melakukan istirahat di luar jam istirahat. Pada saat menunggu bahan untuk dikirm banyak pekerjaan yang berhenti dikarenakan hal tersebut. Hal ini sangat merugikan khususnya bagi pemilik bangunan yang menginginkan agar bangunan dapat diselesaikan dengan cepat atau tepat waktu. ${ }^{(16)}$

Hutabarat (2017) dalam bukunya mengatakan Sikap tubuh dalam melakukan pekerjaan sangat dipengaruhi oleh bentuk,ukuran, susunan,dan penempatan mesin dan peralatan serta perlengkapan kerja; juga bentuk, ukuran dan penempatan alat kendali serta alat petunjuk, cara kerja mengoperasikan mesin dan peralatan yang merinci macam gerak, arah dan kekuatannya yang harus dilakukan. ${ }^{(17)}$

\section{KESIMPULAN DAN SARAN}

Berdasarkan hasil data dalam persentase keluhan sakit yang dialami oleh pekerja UD. Satria menunjukkan hasil skor pada kategori tidak sakit persentase terbesar dengan nilai $86 \%$ pada lengan atas kiri, kategori agak sakit terbesar dengan nilai $57 \%$ pada bagian lengan atas kanan, lengan bawah kanan dan lutut kiri, kategori sakit terbesar dengan nilai $100 \%$ pada leherr bagian atas dan leher bagian bawah, kategori sangat sakit terbesar dengan nilai $57 \%$ pada bagian pinggang.

Lalu pada perhitungan skor individu dengan skala likert yang sudah ditentukan mendapatkan hasil skor mulai dari yang terendah yaitu skor $27 \mathrm{dan}$ yang tertinggi yaitu skor 38. Jika diklasifikasi subjektivitas tingkat risiko otot skeletal pada para responden mendapatkan hasil sedang seluruhnya dan diperlukan penanganan lebih lanjut serta membutuhkan perubahan segera.

Saran yang dapat diberikan kepada UD. Satria yaitu untuk mewajibkan para pekerja untuk memakai alat pelindung diri seperti masker, sarung tangan dan googles, serta adanya penyediaan fasilitas penunjang seperti kotak P3K agar saat terjadi kejadian yang tidak diinginkan dapat diatasi dengan cepat. Dari hasil selama penelitian saran untuk pekerja yaitu melakukan kegiatan peregangan otot sebelum memulai bekerja atau saat istirahat. Jika memungkinkan pihak perusahaan perlu memberikan kursi sekaligus meja agar pekerja dapat bekerja dengan nyaman dan tidak mengalami nyeri otot pada badan. Karena beberapa kegiatan atau postur yang memerlukan perancangan alat baik berupa meja atau. landasan, alat bantu dan juga tata letak dari fasilitas yang terdapat di stasiun kerja. Penelitian ini masih terdapat kekurangan terutama pada usulan perbaikan sehingga dapat dilakukan penelitian yang lebih baik pada penelitian selanjutnya untuk memberi variasi ilmu pengetahuan terutama mengenai analisa postur kerja

\section{DAFTAR PUSTAKA}

1. Hardianti A. Faktor Yang Berhubungan Dengan Keluhan Nyeri Otot Skeletal (Musculoskeletal Disorders) Pada Pekerja Bongkar Muat Di Pelabuhan Soekarno Hatta Makassar Tahun 


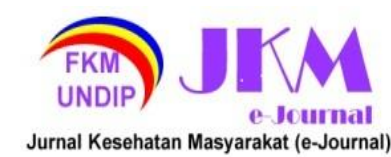

2018. Skripsi. 2018;1(Departemen K3 FKM Universitas Hasanuddin):82.

2. Suma'mur, P K. Higiene Perusahaan dan Kesehatan Kerja. Jakarta: PT. Toko Gunung Agung; 1996.

3. Badriyyah ZH, Setyaningsih Y, Ekawati. Hubungan faktor individu, durasi kerja, dan tingkat risiko ergonomi terhadap kejadian musculoskeletal disorders pada penenun songket pandai sikek. J Kesehat Masy. 2021;9(6):77883.

4. Suma'mur, P K. Higiene perusahaan dan keselamatan kerja. Jakarta: PT. Toko Gunung Agung; 1996.

5. Atmojo EBT. Analisis Nordic Body Map Terhadap Proses Pekerjaan Penjemuran Kopi Oleh Petani Kopi. J Valtech. 2020;3(1):30-3.

6. Bukhori E. Hubungan Faktor Risiko Pekerjaan Dengan Terjadinya Keluhan Musculoskeletal Disorder (MSDs) Pada Tukang Angkat Beban Pnambang Emas Di Kecamatan Cilograng Kabupaten Lebak Tahun 2010. Hub Fakt Risiko Pekerj Dengan Terjadinya Keluhan Musculoskelet Disord Pada Tukang Angkut Beban Penambang Emas Di Kec Cilograng Kabupaten Lebak Tahun 2010. 2010;1-93.

7. OSHA. Ergonomics: The Study of Work. OSHA 3125. U.S: Occupational Safety and Health Administration; 2000.

8. Dewi NF. Identifikasi Risiko Ergonomi dengan Metode Nordic Body Map Terhadap Perawat Poli RS X. J Sos Hum Terap. 2020;2(2):125-34.

9. Tarwaka. Ergonomi Indutri: Dasar-Dasar Ergonomi dan Implementasi di Tempat Kerja. SURAKARTA: Harapan Press; 2014.

10.Firmansyah. Evaluasi Postur Kerja Dengan Metode Owas Terhadap Keluhan Muskuloskeletal Pada Pekerja Manual Handling Di Pt Iskandar Indah Printing Textile Surakarta. Surakarta; 2014.

11. Ramdhani D, Zalynda PM. Analisis Postur Kerja Pengrajin Handycraft Menggunakan Nordic Body Map Dan Metode Rapid Upper Limb Assessment (Rula). Institutional respositories Sci journals [Internet]. 2018;1-13. Available from: Dani Ramdhani1), IR.Putri Mety Zalynda, MT2)

12.Sujoso A, Siskandini R. Identifikasi Keluhan Muskuloskeletal Dengan Nordic Body Map Ditinjau Dari Kesalahan Posisi Duduk Dan
Indeks Kesegaran Jasmani Pada Perajin Perak Di Desa Pulo Kecamatan Tempeh Kabupaten Lumajang. 2009;5(2).

13.Wicaksono B. Faktor Yang Berhubungan Dengan Gangguan Nyeri Punggung Bawah Pada Bidan Saat Menolong Proses Persalinan (Studi di RSUD Bhakti Dharma Husada Surabaya). 2012;

14.Mahardika T, Pujotomo D. Perancangan Fasitilas Kerja Untuk Mengurangi Keluhan Musculoskeletal Disorders (Msds) Dengan Metode Rappid Entire Body Assesment Pada Pekerja Pembuatan Paving Dan Batako Pada Ukm Usaha Baru. J@Ti Undip J Tek Ind. 2014;9(2).

15.Putri RO, Jayanti S, Kurniawan B, Masyarakat FK, Masyarakat FK. Pada Pekerja Pabrik Tahu X Di Kota Semarang. 2021;9(November):73340.

16.Briansah AO. Analisa Postur Kerja Yang Terjadi Untuk Aktivitas Dalam Proyek Konstruksi Bangunan Dengan Metode Rula Di CV.Basani. 2018;1-70. Available from: https://dspace.uii.ac.id/handle/123456789/1189 5

17.Hutabarat Y. Dasar-dasar pengetahuan ergonomi. Malang: Media Nusa Creative; 2017. 